
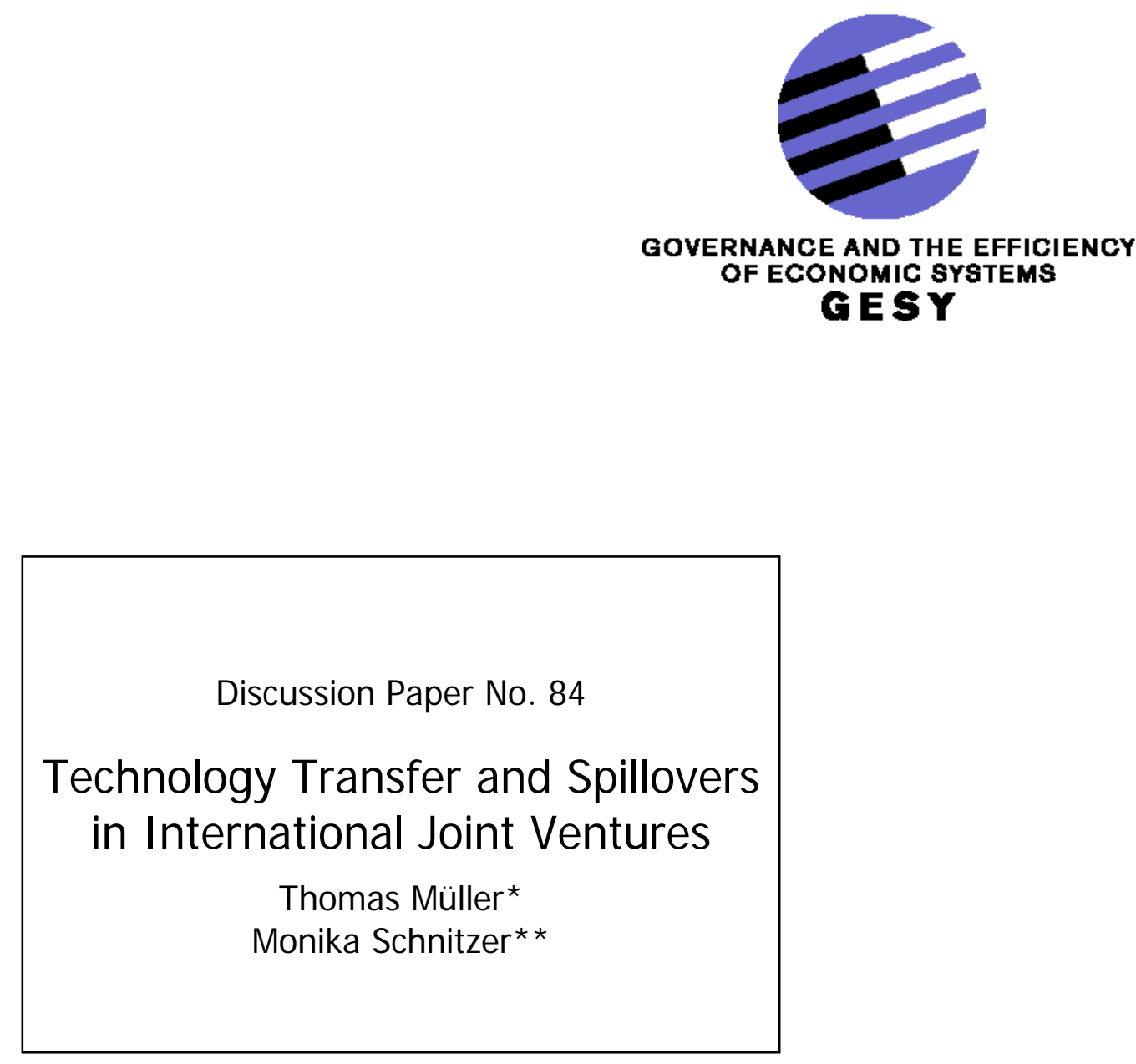

October 2005

*Thomas Müller, Bundesanstalt für Finanzdienstleistungsaufsicht (BaFin), International/Financial Markets Department, Georg-von-Boeselager-Str. 25, 53117 Bonn, Germany, Tel.: +49 2284108 3732, Fax.: +49 228410863732. thomas.mueller3@bafin.de

**Monika Schnitzer, Department of Economics, University of Munich, Akademiestr. 1/III, 80799 Munich, Germany, Tel.: +49 892180 2217, Fax.: +49 892180 2767. schnitzer@Irz.uni-muenchen.de

Financial support from the Deutsche Forschungsgemeinschaft through SFB/TR 15 is gratefully acknowledged.

Sonderforschungsbereich/Transregio $15 \cdot$ www.gesy.uni-mannheim.de 


\title{
Technology Transfer and Spillovers in International Joint Ventures
}

\author{
Thomas Müller* Monika Schnitzer ${ }^{\dagger}$
}

October 2005

\begin{abstract}
It is often argued that multinationals are reluctant to transfer technology due to the fear of spillovers. We show that this need not be the case if host country policies like taxation are taken into account. Furthermore, we examine the incentives the multinational and the host country have to engage in an international joint venture. We show why a multinational may agree to enter a joint venture even though this gives rise to spillovers. Surprisingly, we find that a joint venture is sometimes not in the interest of a host country, despite the prospect of spillovers.
\end{abstract}

JEL-classification numbers: D43, F21, F23, L13, P31, O12.

Keywords: Foreign Direct Investment, International Joint Ventures, Technology Transfer, Technology Spillovers, Multinational Firms

Financial support through SFB-TR-15 and DFG-grant Schn 422/2-1/2 is gratefully acknowledged.

\footnotetext{
*Thomas Müller, Bundesanstalt für Finanzdienstleistungsaufsicht (BaFin), International/Financial Markets Department, Georg-von-Boeselager-Str. $\quad$ 25, 53117 Bonn, Germany, Tel.: +49 2284108 3732, Fax.: +49 2284108 63732, e-mail: Thomas.Mueller3@bafin.de

${ }^{\dagger}$ Corresponding author: Monika Schnitzer, Department of Economics, University of Munich, Akademiestr. 1/III, 80799 Munich, Germany, Tel.: +49 892180 2217, Fax.: +49 892180 2767, e-mail: schnitzer@lrz.uni-muenchen.de
} 


\section{Introduction}

Multinational firms are frequently confronted with restrictions placed on the ownership structure of their foreign operation by local governments. ${ }^{1}$ In particular, developing and transition countries that require shared ownership expect to benefit from technology spillovers. Multinationals, on the other hand, are not always happy about such forced international joint ventures, precisely because of the risk of involuntary spillovers. $^{2}$

In this paper we examine the incentives a multinational has to transfer technology when there are spillover effects. In particular, we study whether it is indeed in the local government's best interest to require a joint venture agreement and whether it is in the multinational's interest to oppose such a requirement. For this purpose, we look at how the ownership structure of a multinational subsidiary affects the incentives the multinational has to transfer technology and the incentive the local government has to support the multinational's activities.

In our model, we consider a multinational investor who decides how much technology to transfer to a host country when there are potential spillovers. As intuition would suggest, we find that the larger the risk of spillovers, the less the multinational is inclined to transfer the technology.

However, this result no longer holds if we allow the host country to play a more active role. We examine two different host country policy instruments - taxation and local infrastructure investment. We find that these policy instruments help the multinational and the host country to align their interests with respect to spillovers. Furthermore, our analysis shows that in general spillovers need not have a negative effect on the incentive to transfer technology.

We also examine how the incentives of both parties can be controlled by means of the ownership structure in an international joint venture. In our reference case, where the host country does not play an active role, we find that both multinational and host country have

\footnotetext{
${ }^{1}$ The views expressed in this paper are those of the authors and do not reflect those of BaFin. We would like to thank Jonathan Eaton and an anonymous referee for helpful comments and suggestions.

${ }^{2}$ Such restrictions have been and still are prominent in countries like Russia, China, India, Indonesia, the Republic of Korea and many others (UNCTC 1987). Moreover, in cases of privatization governments have often retained a substantial share of the privatized assets (Bortolotti, Fantini and Siniscalco 2004, Maw 2002).
} 
conflicting interests with respect to sharing cash flow rights. However, a multinational may voluntarily agree to a joint venture if this induces the host country to introduce a more favorable policy vis à vis the foreign subsidiary. On the other hand, there are also circumstances where it is not in the interest of the host country to form a joint venture. This conclusion should be of particular interest to countries in Central and Eastern Europe and to other transition countries where sharing of ownership is often required by host country governments.

Our paper relates to two strands of literature. The first is the theoretical literature on foreign direct investments and sovereign risks. These papers study the implications for multinational investment where host countries cannot commit to not expropriating the investment. ${ }^{3}$ Eaton and Gersovitz (1984) show that the threat of nationalization may induce the foreign investor to choose an inefficient technology that makes nationalization less attractive to the host country. Schnitzer (2002) points out that the multinational may opt for a joint venture if this helps alleviate the sovereign risk problem. ${ }^{4}$

When we incorporate spillovers in our model, we find that these further reduce the multinational's incentive to transfer technology efficiently. However, such spillovers are more likely to occur if the host country has a share in the foreign subsidiary. Hence, an interesting question we address is whether it can still be in the interest of a multinational to form a joint venture in order to alleviate the sovereign risk, even if this further increases the risk of spillovers.

The second strand of literature is concerned with foreign direct investments and spillovers. A number of empirical studies have attempted to assess the impact of foreign direct investment on the productivity of domestic firms. ${ }^{5}$ But the conclusions reached in these studies are mixed. ${ }^{6}$ Kokko (1994), Borensztein et al. (1998) and Xu (2000) show that positive spillovers are more

\footnotetext{
${ }^{3}$ The seminal article here is Eaton and Gersovitz (1983). See also Eaton (1993) and Eaton and Fernandez (1995) for surveys on sovereign risk in the context of sovereign debt.

${ }^{4}$ Konrad and Lommerud (2001) show that asymmetric information between the MNE and the host country concerning intra-firm trade between the MNE and its foreign affiliate is another possibility for alleviating the hold-up problem in FDI. Selling shares of the affiliate to locals give the host government a further incentive to reduce taxation.

${ }^{5}$ See Saggi (2002) or Blomström and Kokko (1998) for recent surveys on international technology transfer and spillovers.

${ }^{6}$ Görg and Strobl (2001) review the literature on multinational companies and productivity spillovers. They argue that the empirical methods used, and whether cross-section or panel analysis is employed, may have an effect on the empirical results.
} 
likely if the technology gap between foreign and domestic firms is not too large and if a minimum threshold of human capital exists. Aitken and Harrison (1999) on the other hand find negative spillovers from foreign investment on domestically owned plants and state that the gains from FDI appear to be entirely captured by joint ventures. ${ }^{7}$

Other empirical studies have examined the interaction of spillovers and the ownership structure in joint ventures. Blomström and Sjöholm (1999) argue that local participation in international joint ventures facilitates spillovers. This, in turn, reduces the incentive for the multinational to transfer technology and management skills. Their empirical results confirm that domestic establishments benefit from spillovers in terms of productivity levels. However, the degree of foreign ownership does not affect its extent. In contrast, Dimelis and Louri (2002) find evidence that the degree of foreign ownership matters, and that productivity spillovers are stronger when foreign firms are in minority positions. Similarly, Smarzynska Javorcik (2004) reports positive spillovers from joint ventures with shared ownership in Lithuania, but not from fully owned foreign investments.

As we will show in our model, the impact on technology spillovers of foreign direct investment in general and ownership structures in particular is not as clear cut as is often assumed. This may help to explain why the empirical evidence is indeed mixed.

The paper is organized as follows. Section 2 introduces the model. In Section 3 we consider the multinational's technology transfer for the benchmark case where the host country plays no active role. Section 4 analyzes the impact of spillovers on technology transfer when the host country can tax the foreign subsidiary. In section 5, we reconsider these effects for the case where the host country can engage in infrastructure investments. Section 6 discusses empirical implications of the model, while the final section concludes.

\footnotetext{
${ }^{7}$ Other studies that found evidence for negative spillovers include Haddad and Harrison (1993) and Djankov and Hoekman (2000).
} 


\section{The Model}

Consider a multinational enterprise (MNE) that is engaged in an investment project in a host country (HC). The project generates a stochastic return of $R$ with probability $q$ and 0 with probability $(1-q)$. This probability is affected by MNE's decision to transfer technology. For example, MNE may decide on the level of investment in training local workers and managers, in marketing the goods produced, and in transferring or upgrading technology. Without loss of generality, we assume that MNE chooses $q \in(0,1)$ directly at cost $K(q) .{ }^{8} K(q)$ is an increasing, strictly convex function with $K^{\prime}(0)=0$ and $\lim _{q \rightarrow 1} K(q)=\infty$. The last assumption implies that, for $q$ sufficiently close to $1, K^{\prime \prime \prime}(q)>0$. To guarantee uniqueness of the solutions for the following maximization problems, we assume $K^{\prime \prime \prime}(q)>0$ for all $q \in(0,1)$.

MNE and $\mathrm{HC}$ can engage in a joint venture for sharing cash flow rights. In this case, $\alpha$ denotes MNE's share of the net profits, and $(1-\alpha)$ HC's share, respectively. However, $\mathrm{HC}$ has no funds to compensate MNE for such a transfer of cash flow rights because it is credit constrained. Note that, even if MNE and HC share cash flow rights, the decision about technology transfer $q$ is taken by MNE alone. The costs of this technology transfer accrue to the investment project. Therefore, it is assumed that a substantial part of these costs will be in local currency and thus HC can share these costs even without access to international capital markets or hard currency.

If the project is carried out as a joint venture, there is a potential spillover $S$ from MNE to HC that increases HC's payoff. To capture the reason why MNE might be worried about spillovers, we assume that the spillover reduces MNE's payoff. The size of the effective spillover depends on two things. It depends firstly on MNE's decision to transfer technology, q. This reflects the fact that the gain from a spillover to HC is larger the better the technology transferred. And secondly, it depends on HC's ownership share $(1-\alpha)$. This captures the idea that HC can learn about the technology if, and only if, it has a stake in the project and hence access to business secrets. Thus, the effective spillover is equal to $q(1-\alpha) S$.

\footnotetext{
${ }^{8}$ The investment project may also involve some fixed cost for setting up the project. Since our focus is on the technology transfer, we normalize these set up costs to zero.
} 
The spillover can be efficient in the sense that the direct reduction of the multinational's payoff is smaller than the benefit for the domestic firm and inefficient in the reverse case. In order to be able to vary the efficiency of the spillover, we introduce an efficiency parameter $\beta>0$. For $\beta=1$ the effective spillover is symmetric, i.e. the loss for MNE equals the benefit to $\mathrm{HC}$. If $\beta<1$ the effective spillover is efficient and is inefficient for $\beta>1$.

$\mathrm{HC}$ can take an active role in potentially two ways. It can choose to tax the investment project, or it can undertake an investment to make the project more profitable. We consider the two possibilities in turn. In scenario 1 , the host country chooses $T$, a lump sum tax to be paid in the case of success. In scenario 2, $\mathrm{HC}$ chooses an investment $M$ that directly benefits the project. $M$ may be interpreted as an investment in local infrastructure. The difference between the two scenarios is that the tax $T$ can only be raised if the project has been successful, while the investment $M$ is spent independently of the project's success. Thus, $M$ cannot be interpreted as just a negative tax, i.e. a subsidy. Furthermore, $T$ is a one-to-one transfer from the project to the host country. $M$ comes at a cost of $C(M)$, borne by $\mathrm{HC}$, where $C(M)$ is an increasing, strictly convex function with $C^{\prime}(0)=0$. We assume that $\mathrm{HC}$ is able to finance this infrastructure investment in local currency.

The purpose of our analysis is to investigate how the host country's policies affect the multinational firm's incentive to transfer technology. Therefore, we assume that HC commits to its policy $T$ or $M$ before MNE chooses $q \cdot{ }^{9}$ So the time structure of the model is as follows. First HC decides about $T$ or $M$. Then MNE chooses $q$. Finally, the payoffs are realized.

We can now summarize the payoffs for both parties in the two scenarios. In scenario 1 , where $\mathrm{HC}$ chooses tax $T$, the parties' payoffs are

$$
U_{M N E}^{T}=q \alpha[R-T]-q(1-\alpha) \beta S-\alpha K(q),
$$

\footnotetext{
${ }^{9}$ In our one period model this assumption is necessary to ensure that HC does not fully expropriate the returns of the project through taxation. Of course, in a multiperiod setting, HC could modify its policy over time. See Schnitzer (1999) for an analysis of such a repeated interaction between HC and MNE in the absence of spillovers.
} 
and

$$
U_{H C}^{T}=q[(1-\alpha)[R-T+S]+T]-(1-\alpha) K(q) .
$$

In scenario 2, where $\mathrm{HC}$ chooses investment $M$, payoffs are

$$
U_{M N E}^{M}=q \alpha[R+M]-q(1-\alpha) \beta S-\alpha K(q)
$$

and

$$
U_{H C}^{M}=q(1-\alpha)[R+M+S]-C(M)-(1-\alpha) K(q)
$$

\section{Spillovers and Technology Transfer}

As a reference case, we first describe MNE's incentive to transfer technology if HC does not play an active role. For this purpose, we solve the model for both $T$ and $M$ equal to zero.

Consider MNE's decision on how much to invest in transferring technology. MNE maximizes

$$
U_{M N E}=q \alpha R-q(1-\alpha) \beta S-\alpha K(q)
$$

Given the assumptions about $K(q)$, the optimal level of investment $q$ is uniquely characterized by the following first order condition:

$$
K^{\prime}(q)=R-\frac{1-\alpha}{\alpha} \beta S
$$

Note that $q$ depends on $\alpha$, due to the existence of spillovers. Using the implicit function theorem, it is straightforward to show that $q(\alpha, S)$ increases in $\alpha$ and decreases in $S$. How these two parameters affect the parties' payoffs is summarized in the following Result. ${ }^{10}$

Result 1 MNE's payoff strictly decreases in $S$, whereas HC's payoff reaches a maximum at $S>0$. Overall welfare strictly decreases in $S$ for symmetric and inefficient spillovers, $\beta \geq 1$. For efficient spillovers, $\beta<1$, welfare reaches a maximum at $S>0$.

\footnotetext{
${ }^{10}$ The proofs for this and all the following results and lemmas are summarized in an Appendix that is posted on the following website: http://www.vwl.uni-muenchen.de/ls_schnitzer/english/research/schnitzer.htm
} 
The result shows that there is a clear conflict of interest between both MNE and HC. MNE loses from potential spillovers. To limit the damage it suffers from the spillovers, it reduces its technology transfer. $\mathrm{HC}$, on the other hand, benefits from the potential to learn from MNE. Its preferred spillover level is strictly positive. ${ }^{11}$ From a welfare point of view, spillovers are bad, not only if they are inefficient, but even if they are symmetric. The reason for this is that they make MNE choose an inefficiently low level of technology transfer, thus reducing the potential for joint profits. Only if spillovers are efficient can their overall impact on welfare be positive, provided that the efficiency gain through spillovers is not outweighed by the efficiency loss due to a smaller technology transfer.

Let us consider next how the ownership structure of a joint venture affects payoffs and efficiency.

Result 2 MNE's payoff strictly increases in $\alpha$, whereas $H C$ 's payoff reaches a maximum at $\alpha<1$. Overall welfare strictly increases in $\alpha$ for symmetric and inefficient spillovers, $\beta \geq 1$. For efficient spillovers, $\beta<1$, welfare reaches a maximum at $\alpha<1$.

This result confirms the conflict of interest between the two parties. HC can benefit from the investment through $R$ or $S$, only if it receives a share of its profits. MNE, on the other hand, loses when sharing the profits. Since this, in turn, has a negative impact on the technology transfer, overall welfare suffers unless the spillover is sufficiently efficient.

\section{Spillovers and Taxation by the Host Country}

We now turn to the question of how the host country's tax policy affects MNE's technology transfer and vice versa. Recall that MNE maximizes (1). The optimal level of investment $q$ is now uniquely characterized by the following first order condition:

$$
K^{\prime}\left(q^{T}\right)=R-T-\frac{1-\alpha}{\alpha} \beta S
$$

\footnotetext{
${ }^{11}$ Note that HC's payoff is not strictly increasing for infinite $S$, due to the negative impact of $S$ ond MNE's choice of $q$.
} 
In this scenario there are two things that may keep MNE from investing in technology transfer $q$ : potential spillover $S$ and HC's taxation $T$. We know that a potential spillover $S$ has a direct negative impact on MNE's incentive to invest in $q$. Furthermore, $q^{T}(T, \alpha)$ is a strictly decreasing function of $T$ for all $T \in\left(0, R-\frac{1-\alpha}{\alpha} \beta S\right)$.

$\mathrm{HC}$, on the other hand, now has three alternative ways of benefiting from the investment project: through a share in the profits, through spillovers and through taxation. When deciding on $T$, HC takes into account the effect of $T$ on $q^{T}(T, \alpha)$ and thus on the likelihood of gaining through taxes, profits and spillovers.

$\mathrm{HC}$ maximizes (2). In the Appendix we prove that HC's maximization problem has a unique interior solution $T^{*}(\alpha, S) \in\left(-(1-\alpha) \frac{\beta-\alpha \beta+\alpha}{\alpha} S, R-\frac{1-\alpha}{\alpha} \beta S\right) .{ }^{12}$ Hence, $T^{*}(\alpha ; S)$ satisfies the following first order condition:

$$
\frac{d q^{T}(T)}{d T}\left[(1-\alpha) \frac{\beta-\alpha \beta+\alpha}{\alpha} S+T^{*}\right]+\alpha q^{T}(T)=0 .
$$

Using the implicit function theorem, we can derive the following Lemma.

Lemma 1 The optimal taxation $T^{*}(\alpha, S)$ strictly decreases in $S$.

$\mathrm{HC}$ reduces taxation in order to encourage the technology transfer if it expects to gain from spillovers.

Spillovers now have two effects on MNE's technology transfer, a negative direct effect and a positive indirect effect via $T$. Which of these effects dominates is a priori not clear. The overall effects on technology transfer and payoffs are summarized in the following Result.

Result 3 (i) For inefficient spillovers, $\beta>1$, S has a negative impact on technology transfer $q^{T}$, and on the payoffs of both MNE and $H C$.

(ii) For efficient spillovers, $\beta<1, S$ has a positive impact on technology transfer $q^{T}$, and on the payoffs of both MNE and $H C$.

\footnotetext{
${ }^{12}$ See Lemma $\mathrm{A}$ in the Appendix.
} 
(iii) For symmetric spillovers, $\beta=1, S$ has no effect on the technology transfer $q^{T}$ or on either of the parties payoffs.

There are two interesting observations to be made. Firstly, we find that, in contrast to what we have seen in Section 3, a potential spillover need not in general reduce the incentive to transfer technology. Whether or not it does so depends on the efficiency of the spillover. Secondly, we find that HC's tax policy aligns the interests of both MNE and HC with respect to potential spillovers. Spillovers either hurt both or benefit both, depending on their efficiency. How does this come about?

Note that, when deciding on $T, \mathrm{HC}$ takes into account the overall impact of $T$ and $S$ on MNE's incentive to transfer technology. If spillovers are efficient, they allow HC to benefit from the project in a more efficient way than through taxation. So HC cuts taxes to encourage MNE's technology transfer. MNE gains more from this tax cut than it loses from spillovers. As a consequence, the technology transfer increases and both $\mathrm{HC}$ and MNE are better off.

If, instead, spillovers are inefficient, HC's tax cut does not fully compensate MNE's loss from spillovers. So technology transfer is reduced and both sides are worse off.

A special case emerges if the spillover is symmetric, $\beta=1$. In this case, the optimal tax rate compensates exactly for the spillover such that the optimal investment remains unchanged. To be more precise, the taxation will be lowered such that the sum of tax rate and spillover is equal to the taxation when there is no spillover, i.e. $T^{*}(\alpha ; S)=T^{*}(\alpha, 0)-\frac{1-\alpha}{\alpha} S$. Hence, for $\beta=1$ taxation and spillover are perfect substitutes from HC's point of view.

How are the incentives of the two parties affected by a change in the ownership structure? In Section 3 above we have seen that MNE's payoff increases in $\alpha$. Is this still the case if HC's policy is taken into account? Using the implicit function theorem, we can derive the following Lemma.

Lemma 2 The optimal tax $T^{*}(\alpha ; S)$ strictly increases in $\alpha$, i.e. decreases in $(1-\alpha)$. Intuitively, the higher the share of profits $(1-\alpha)$ that goes directly to $\mathrm{HC}$, the less $\mathrm{HC}$ will tax in order to increase the expected profits of the joint venture. So the overall effect of $\alpha$ on 
MNE's payoff is no longer clear. The following Result summarizes the effects of an increase in the multinational's share $\alpha$ on the payoffs of the two parties and on the efficiency of the project.

Result 4 (i) An increase in $\alpha$ has an ambiguous effect on MNE's payoff. For large values of $\alpha$, there exist cases where MNE benefits from giving up some share of the project to $H C$.

(ii) For efficient or symmetric spillovers, $\beta \leq 1, H C$ 's payoff and the efficiency of the project are strictly decreasing as $\alpha$ increases.

(iii) For inefficient spillovers, $\beta>1$, there exist cases where $H C^{\prime}$ 's payoff and the efficiency of the project increase as a increases. Moreover, there exist cases where HC's payoff and the efficiency of the project are maximized if ownership of the project is not shared.

Result 4 shows that there are circumstances where a joint venture agreement is mutually beneficial even though this gives rise to spillovers. In contrast to our result above, we now find that MNE may benefit from sharing profits. The reason for this is that, by letting HC participate in profits and spillovers, MNE can achieve a lower taxation.

On the other hand, we see that HC may no longer find it optimal to require a joint venture. In contrast to before, $\mathrm{HC}$ now has means other than a joint venture for benefiting from the project. So if the effects of potential spillovers in case of a joint venture are too harmful for the technology transfer, $\mathrm{HC}$ may choose to restrict itself to taxation alone. This result gives a rationale for why full ownership of the project by MNE can sometimes be in the interest of $\mathrm{HC}$ even though only shared ownership gives rise to a spillover. This finding is particularly interesting for countries in transition or Eastern European countries where multinationals are sometimes restricted to shared ownership arrangements by host governments. As we show, the negative effects associated with shared ownership, i.e. the reduced incentive for MNE to invest further, can become very strong. And, thus, it can be optimal for $\mathrm{HC}$ to restrict its own share of the project or even not to share ownership at all, but rather to take advantage of a large expected tax revenue. 
From a welfare point of view, however, we find a stronger case for joint ventures when taxation is taken into account. For $\beta=1$, joint profits now strictly decrease in $\alpha$, whereas without taxation they increase. For $\beta<1$, joint profits now strictly decrease in $\alpha$ though this was not always the case in Section 3. And, for $\beta>1$, joint profits may decrease in $\alpha$ although without taxation they were strictly increasing.

\section{Spillovers and Investment by the Host Country}

Now we ask how both parties' incentives are affected by a potential spillover if HC does not impose a tax on the project but instead has the option for undertaking some infrastructure investment $M$ in order to increase the return to the project. MNE maximizes (3) by choosing the optimal level of technology transfer $q$. This transfer is now a strictly increasing function of $M$ for all $M>0$.

When $\mathrm{HC}$ decides on $M$, it takes into account the effect on $q^{M}(M, \alpha)$ and thus on its expected profits. HC maximizes (4). In the Appendix, we show the conditions under which HC's payoff is maximized at $M^{*}(\alpha, S) \in(\underline{M}, \infty)$, where $\underline{M}=\max \left\{0, \frac{1-\alpha}{\alpha} \beta S-R\right\} .{ }^{13}$ Hence, the optimal investment $M^{*}(\alpha, S)$ satisfies the following first order condition:

$$
\frac{d q^{M}(M)}{d M}\left[(1-\alpha) \frac{\beta-\alpha \beta+\alpha}{\alpha} S\right]+q^{M}(M)(1-\alpha)-C^{\prime}(M)=0 .
$$

Note that, if $\alpha=1, \mathrm{HC}$ will choose $M^{*}(1, S)=0$. Thus, the host country has an incentive to invest in local infrastructure if, only if, ownership of the project is shared. Using the implicit function theorem we can derive the following Lemma.

Lemma 3 The optimal infrastructure investment $M^{*}(\alpha, S)$ strictly increases in $S$.

By investing in local infrastructure HC encourages MNE to transfer technology. The larger $S$ is, the more $\mathrm{HC}$ is interested in doing so.

The following Result summarizes how our previous insights are changed if $\mathrm{HC}$ engages in infrastructure investment rather than monetary transfers through taxation.

\footnotetext{
${ }^{13}$ See Lemma B in the Appendix.
} 
Result 5 (i) An increase in $S$ can lower technology transfer $q^{M}$ and the payoffs of both parties even if the spillover is efficient, $\beta<1$.

(ii) An increase in $S$ can increase technology transfer $q^{M}$ and the payoffs of both parties even if the spillover is inefficient, $\beta>1$.

We find that, like in the scenario with taxation, the presence of a potential spillover need not in general reduce the incentive to transfer technology and so harm MNE's payoff. What is new, however, is that an efficient spillover no longer automatically has a positive impact, nor does an inefficient spillover automatically have a negative impact. The crucial issue now is how strongly the spillover encourages HC to invest in infrastructure. Whenever a potential spillover leads to a strong incentive to invest in infrastructure, the multinational is given a stronger investment incentive as well. This, in turn, has a positive effect on payoffs. Obviously, the host country's incentive to invest depends on the nature of the investment cost for local infrastructure. If this cost is very low, then the efficiency of the infrastructure investment more than outweighs a potential efficiency loss due to spillovers. So it is the joint efficiency of infrastructure investment and spillovers that matters now.

How are the incentives of both parties affected by a change in the ownership structure? As before, we know that lowering the multinational's ownership share $\alpha$ a priori reduces its incentive to transfer technology. On the other hand, the incentive for $\mathrm{HC}$ to invest in local infrastructure should increase as we state in the following lemma.

Lemma 4 The optimal infrastructure investment $M^{*}(\alpha, S)$ decreases in $\alpha$.

This, in turn, has an indirect positive effect on the incentive for MNE. Whether one of the effects dominates is not clear. The following Result points out how the impact of ownership shares may change in the case of an infrastructure investment.

Result 6 (i) An increase in $\alpha$ has an ambiguous effect on MNE's payoff. For large values of $\alpha$, there exist cases where MNE benefits from giving up some share of the project to $H C$. 
(ii) There exist cases where HC's payoff and the efficiency of the project increase over some interval of $\alpha<1$, even if the spillover is efficient, $\beta<1$.

As we see, there are again cases where the multinational voluntarily agrees to a joint venture. ${ }^{14}$ As before, the rationale is to give $\mathrm{HC}$ an incentive to invest in infrastructure. Moreover, we find that it is sometimes efficient and in the interest of $\mathrm{HC}$ to restrict its ownership share. Surprisingly, this can happen even if the spillover is efficient, $\beta<1$. Why is this so? Whether or not $\mathrm{HC}$ wants to hold a share of the project depends on the exact nature of the investment cost. If this cost is too high relative to the return on investment, $\mathrm{HC}$ has little incentive to invest. This, in turn, results in only a small positive effect on the incentive to transfer technology by MNE. So, in a way, the less cost effective or efficient the infrastructure investment, the less this can be compensated by an efficient spillover.

Note finally, that, in this scenario, it cannot be in HC's interest to refrain from participating in a joint venture. Without taxation, $\mathrm{HC}$ can benefit from the project only if it holds a share in the project.

\section{Empirical Implications}

Our model gives rise to a number of empirical predictions. From Result 1 in Section 3, we can derive the following hypothesis.

Hypothesis 1 Suppose that the host country takes no active role in taxing or supporting a multinational's investment. Then the larger the potential for a spillover, the smaller MNE's incentive to transfer technology.

But in Sections 4 and 5 we found that a local government should be interested in supporting MNE's investment if it expects to benefit from spillovers, as stated in Lemmas 1 and 3.

Hypothesis 2 The larger the potential for a spillover, the smaller the risk of excessive taxation and the larger the contribution of the local government to local infrastructure.

\footnotetext{
${ }^{14}$ Asiedu and Esfahani (2001) find evidence that host country characteristics that increase productivity of local assets tend to lower the foreign equity share. This might be in the interest of the foreign investor because it provides an incentive for the host country to improve its infrastructure and thereby enhance productivity.
} 
If the host country's policy measures are taken into account, then the impact of spillovers on MNE's incentive to transfer technology are no longer always negative, as we have seen in sections 4 and 5. How spillovers affect technology transfer is now related to their efficiency, as described in Results 3 and 5.

Hypothesis 3 Suppose that a host country takes an active role in taxing or supporting a multinational's investment. Then potential spillovers tend to have a positive effect on the incentive to transfer technology if the effective spillover is efficient and a negative effect if the effective spillover is inefficient.

As we see, one crucial issue for testing these hypotheses is how to capture the efficiency of the spillovers. Whether or not MNE loses if HC learns, and by how much, naturally depends on their respective competitive situations. If they are operating in completely different markets, then MNE has little to fear if HC learns from MNE's technology transfer. In this case, the spillover could be called efficient, $\beta<1$. If, on the other hand, they are operating in the same market, it is likely that MNE loses more than HC gains from any spillover. ${ }^{15}$ Thus, this would be a case of inefficient spillover, $\beta>1$. So we can rephrase Hypothesis 3 in the following way.

Hypothesis 4 Suppose that a host country takes an active role in taxing or supporting a multinational's investment. Then potential spillovers tend to have a negative effect on the incentive to transfer technology if MNE and HC compete in the same market, and a positive effect if MNE and $H C$ operate in different markets.

\section{Discussion and Conclusions}

As previous studies have suggested and have often argued, foreign direct investment is a source of the diffusion of knowledge and technology. It is well recognized that sharing ownership with a local partner can reveal a multinational's proprietary knowledge and, in that way, give rise

\footnotetext{
${ }^{15}$ To see this, consider the following example: Suppose MNE acts as a monopolist before the technology transfer, earning monopoly profit $\pi_{M}$. After the spillover occurs, both MNE and HC become duopolists, both earning $\pi_{D}$. For very general demand and cost functions it can be shown that $\pi_{M}>2 \pi_{D}$. So MNE's loss from losing its monopoly position, $\pi_{M}-\pi_{D}$, exceeds HC's gain, $\pi_{D}$.
} 
to technology spillovers. The extent of such technology spillovers depends on the nature of the technology transferred and on the ownership structure in the joint venture.

In contrast to often-voiced arguments, we have shown that potential spillovers do not necessarily keep multinational investors from transfering technology to other countries. The reason is that spillovers are also taken into account by the host country when choosing its policy. If spillovers are an efficient way of participating in the multinational's gain, then the host country may compensate the multinational for its losses through spillovers by choosing appropriate policy measures.

We have also shown that joint ventures may be in the interest of both host country and multinational, even if the multinational cannot be directly compensated for giving up part of its cash flow rights. This is the case if the host country is induced to support the investment through policy measures. On the other hand, there are circumstances where a joint venture is not in the interest of the host country. This insight is particularly interesting to countries in Central and Eastern Europe and to transition countries, where sharing of ownership is often required by host country governments. Their justification for these requirements is that, in this way, the diffusion of knowledge is facilitated and economic growth is spurred. But as we have shown exactly the opposite may occur.

The present analysis sheds some light on how local participation in international joint ventures affects the extent of spillovers. We have argued that the extent of the effective spillover depends not only on the ownership structure but also on the transfer of technology and on the host country's policy. These factors depend on country specific and industry-specific determinants. Whether or not a larger ownership share of the host country firm leads to more spillovers is a priori not clear and can differ across countries and industries. This observation may help explain why the empirical evidence on this issue is mixed. While Blomström and Sjöholm found no effect, Dimelis and Louri, and Smarzynska Javorcic found evidence that the degree of domestic ownership matters with respect to the magnitude of spillovers. Our analysis suggests that more detailed empirical analysis is required to better understand this relationship. 


\section{References}

Aitken, B.J., Harrison, A.E., 1999. Do Domestic Firms Benefit from Foreign Direct Investment? Evidence from Venezuela. American Economic Review, 89(3), 605 - 618.

Asiedu, E., Esfahani, H.S., 2001. Ownership Structure in Foreign Direct Investment Projects. Review of Economics and Statistics, 83(4), 647 - 662.

Blomström, M., Kokko, A., 1998. Multinational Corporations and Spillovers. Journal of Economic Surveys, 12(3), 247 - 277.

Blomström, M., Sjöholm, F., 1999. Technology Transfer and Spillovers: Does local Participation with Multinationals Matter? European Economic Review, 43, 915 - 923.

Borensztein, E., De Gregorio; J., Lee; J.-W., 1998. How does Foreign Direct Investment affect Economic Growth? Journal of International Economics, 45(1), 115 - 135.

Bortolotti, B., Siniscalco, D., Fantini, M., 2004. Privatization around the World: Evidence from Panel Data. Journal of Public Economics, 88(1-2), 305-332.

Dimelis, S., Louri, H., 2002. Foreign Ownership and Production Efficiency: A Quantile Regression Analysis. Oxford Economic Papers, 54(3), 449 - 469.

Djankov, S., Hoekman, B.M. , 2000. Foreign Investment and Productivity Growth in Czech Enterprises. World Bank Economic Review, 14(1), 49 - 64.

Eaton, J., 1993. Sovereign Debt: A Primer. The World Bank Economic Review, 7(2), $137-172$.

Eaton, J., Fernandez, R., 1995. Sovereign Debt, in: Grossman, G.M. and Rogoff, K. (Eds.), Handbook of International Economics, North Holland, Amsterdam, 2031 - 2077.

Eaton, J., Gersovitz, M., 1983. Country Risk: Economic Aspects, in: Herring, R.J. (Ed.), Managing International Risk. Cambridge University Press, Cambridge, U.K., 75 - 108.

Eaton, J., Gersovitz, M., 1984. A Theory of Expropriation and Deviations from Perfect Capital Mobility. Economic Journal, 94(1), 16 - 40.

Görg, H., Strobl, E., 2001. Multinational Companies and Productivity Spillovers: A MetaAnalysis. Economic Journal, 111(475), 723 - 739. 
Haddad, M., Harrison, A., 1993. Are There Positive Spillovers from Direct Foreign Investment? Evidence from Panel Data for Morocco. Journal of Development Economics, $42(1), 51-74$.

Kokko, A., 1994. Technology, Market Characteristics, and Spillovers. Journal of Development Economics, 43(2), 279 - 293.

Konrad, K.A., Lommerud, K.E., 2001. Foreign Direct Investment, intra-firm Trade and Ownership Structure. European Economic Review, 45, 475 - 494.

Maw, J., 2002. Partial Privatization in Transition Economies. Economic Systems, 26, $271-282$.

Saggi, K., 2002. Trade, Foreign Direct Investment, and International Technology Transfer: A Survey. World Bank Research Observer, 17(2), 191-235.

Schnitzer, M., 1999. Expropriation and Control Rights: A Dynamic Model of Foreign Direct Investment. International Journal of Industrial Organization, 17, 1113 - 1137.

Schnitzer, M., 2002. Debt vs. Foreign Direct Investment: The Impact of Sovereign Risk on the Structure of International Capital Flows. Economica, 69(273), 41 - 67.

Smarzynska Javorcik, B., 2004. Does Foreign Direct Investment Increase the Productivity of Domestic Firms? In Search of Spillovers through Backward Linkages. American Economic Review, 94(3).

UNCTC, 1987. Arrangements between Joint Venture Partners in Developing Countries. Advisory Study No. 2, United Nations, New York.

Xu, B., 2000. Multinational Enterprises, Technology Diffusion, and Host Country Productivity Growth. Journal of Development Economics, 62(2), 477 - 493. 